\author{
Contents lists available at www.cmro.in \\ JOURNAL OF CURRENT MEDICAL RESEARCH AND OPINION
}

Journal homepage: http://cmro.in/index.php/jcmro

\title{
To Study The Serum Vitamin -D And Oxidative Stress Status In Rheumatoid Arthritis
}

\section{T.UMA ${ }^{1,2^{*}}$, R.VIJAYARAGHAVAN ${ }^{1}$, S.SENTHILKUMAR ${ }^{1}$,D.S.S.GIRIJA VANI ${ }^{3}$}

1. Department Of Research, Saveetha University, Chennai, Tamilnadu, India.

2. Department Of Biochemistry RIMS ,Srikakulam, Andrapradesh India.

3. Department Of Biochemistry ,Geetham Medical College,Vishakapatnam, Andrapradesh India.

\section{ARTICLE INFO}

\section{Corresponding Author:}

\section{T.UMA}

Department of Research, Saveetha University, Chennai, Tamilnadu, India.

Department Of Biochemistry RIMS

,Srikakulam, Andrapradesh India

Keywords:Rheumatoid arthritis,oxidativestress, vitamin -D

\begin{abstract}
Aim and objectives: Rheumatoid arthritis (RA) is a chronic autoimmune systemic disease characterized predominantly by synovial inflammation, leading to joint destruction. The study was undertaken to analyze the vitamin -D and oxidative stress status in Rheumatoid arthritis
\end{abstract}

Materials and methods: The Study includes Patients diagnosed as RA by using RA factor within the age group of 30 to 60 years and comprised of 20 age matched control group. To assess oxidative stress, serum Malonyldialdehyde (MDA) was by thiobarbituric acid method and antioxidant level was assessed by estimation of serum vitamin $\mathrm{C}$ by dinitrophenyl hydrazine method. And vitamin $\mathrm{D}$ total is estimated by chemiluminescent immunoassay.

Results: There is a significant decreased level of vitamin -D in the RA patients $(37.58 \pm 5.7 \mathrm{ng} / \mathrm{ml})$ as compared to healthy controls $(58.5 \pm 5.6 \mathrm{ngl} / \mathrm{ml})$. There is a a significant increased levels of MDA in the RA patients (7.6 \pm 1.09$)$ as compared to healthy controls $(8.4 \pm 2.8)$. There is a significant decreased level of vitamin -c in the RA patients $(0.6 \pm 0.3 \mathrm{mg} / \mathrm{dl})$ as compared to healthy controls $(1.0 \pm 0.31 \mathrm{mg} / \mathrm{dl})$.

Conclusion: Low levels of Vitamin D deficiency in RA patients is associated with inflammation which leads to Increased oxidative stress status, which may lead to connective tissue degradation leading to joint and periarticular deformities in rheumatoid arthritis.

\section{INTRODUCTION}

Rheumatoid arthritis (RA) is a chronic autoimmune systemic disease characterized predominantly by synovial inflammation, leading to joint destruction. RA affects up to $1 \%$ of the population in the world and is associated with reduced life expectancy (1). Rheumatoid arthritis (RA) is an autoimmune disease of unknown aetiology [2]. Both T and B lymphocytes are involved in the pathogenesis of the disease [3]. The role of $\mathrm{T}$ lymphocytes as well as that of $\mathrm{B}$ lymphocytes in the pathogenesis of RA has been further proved by the therapeutic efficacy of methods affecting both $\mathrm{T}$ and $\mathrm{B}$ lymphocytes, namely the biological agents [4]. Rheumatoid arthritis is a whole body disorder, primarily affecting the synovial joints. Early changes include inflammation and thickening of the synovial membrane. Late changes include destruction of the cartilage along with formation and deposition of pannus in the joint spaces. The inflammation and various symptoms such as fever, loss of weight and weakness is due to the release of a chemical mediator called cytokines. The etiology of the disease could be attributed to genetic and environmental factors; the exact cause is still unknown. Vitamin D could be one of the environmental factors linked to rheumatoid arthritis. (5)

Vitamin D is a steroid hormone involved in bone and calcium metabolism. It is involved in the regulation of calcium homeostasis, as it regulates calcium absorption from the gastrointestinal system [6]. The hormone is synthesized in the skin by the action of ultraviolet irradiation [7]. Vitamin D, as a prohormone, is considered to be able to play potential immune-suppressive roles and to exert an endocrine action on the immune system cells, generating anti-inflammatory and immunoregulatory effects [8]. Vitamin D deficiency may increase the risk for the development of RA [5]. The role of vitamin D deficiency 
in the pathogenesis of RA, as well as the relationship between vitamin $\mathrm{D}$ deficiency and the activity of RA is discussed [9]. Epidemiological data also imply that vitamin D deficiency may be a risk for development of autoimmune and other chronic diseases $[10,11]$. Preliminary studies suggest that low levels of vitamin D may be common in rheumatoid arthritis (RA) [12-15]. More recently, vitamin D deficiency was found in 42 out of 145 postmenopausal women with RA in the USA, with the highest prevalence among African Americans [16,17]. Moreover, some authors reported an inverse relationship between serum levels of vitamin $\mathrm{D}$ metabolites and disease activity or disability in patients with RA or early inflammatory polyarthritis, although conflicting results have been found [18]The relationship between RA and vitamin $D$ has been extensively studied, and the results remain controversial. Several studies show that RA patients have lower levels of vitamin D $[19,20]$. T-cells and cytokines play an important role along with oxygen radicals as superoxide and hydrogen peroxide released by activated macrophages in the progression of rheumatoid arthritis. These reactive oxygen species (ROS) and reactive nitrogen species (RNS) which are thus produced have both beneficial and toxic effects Oxidative stress is the condition when concentration of ROS and RNS becomes deleterious and damage the cells and biological macromolecules and thus the body. Oxidative stress occurs due to disturbed balance between body's antioxidant mechanisms and oxidative stress production and has important role in the development of chronic disease as autoimmunity like RA, cancer etc. [21]. The objective of the study was to evaluate the relationship between vitamin D and RA, as well as the relationship between cxidativestress in RA

\section{Materials and Method:}

The study was carried out at Rajiv Gandhi Institute Of Medical Sciences \& general hospital, Srikakulam, Andhra Pradesh in collaboration with Department of Orthopaedics. The Institutional Ethics Committee approved the study protocol. . The Study includes Patients diagnosed as RA by using RA factor within the age group of 30 to 60 years and comprised of 20 age matched control group. Exclusion criteria were smoking, alcohol intake, narcotic drugs, hypertension, diabetes mellitus, hypothyroidism, hyperthyroidism and any other form of arthritis except RA The study protocol was explained in detail to all the subjects and informed written consent regarding participation in the study was obtained from them. Then $5 \mathrm{ml}$ of blood sample was obtained from the participant under all aseptic precautions. To assess oxidative stress, serum Malonyldialdehyde (MDA) was by thiobarbituric acid method and antioxidant level was assessed by estimation of serum vitamin $\mathrm{C}$ by dinitrophenyl hydrazine method. And vitamin $\mathrm{D}$ total is estimated by chemiluminescent immunoassay .Serum MDA level, serum vitamin $C$ and vitamin $-d$ levels were compared by applying unpaired $t$ test.

\section{Results}

Table 1 shows a significant $(p=0.001)$ decreased levels of vitamin $-D$ in the $R A$ patients $(37.58 \pm 5.7 \mathrm{ng} / \mathrm{ml})$ as compared to healthy controls $(58.5 \pm 5.6 \mathrm{ngl} / \mathrm{ml})$. vitamin $-\mathrm{D}$

\begin{tabular}{|l|l|l|l|}
\hline parameter & Controls & Cases & $\boldsymbol{p}$ value \\
\hline Vitamin -D & $58.5 \pm 5.6$ & $37.58 \pm 5.7$ & $0.001^{*}$ \\
\hline
\end{tabular}

levels show statistically significant decreased in cases compared to controls ( $p=0.0001)$.

Table 1: SHOWING THE MEAN VALUES OF VITAMIN -D IN CONTROLS AND RA

Table 2 shows a significant $(p=0.001)$ increased levels of MDA in the RA patients $(8.4 \pm 2.8)$ as compared to healthy controls $(3.7 \pm 2.8)$. MDA levels show statistically significant increased in cases compared to controls $(p=0.0001)$.

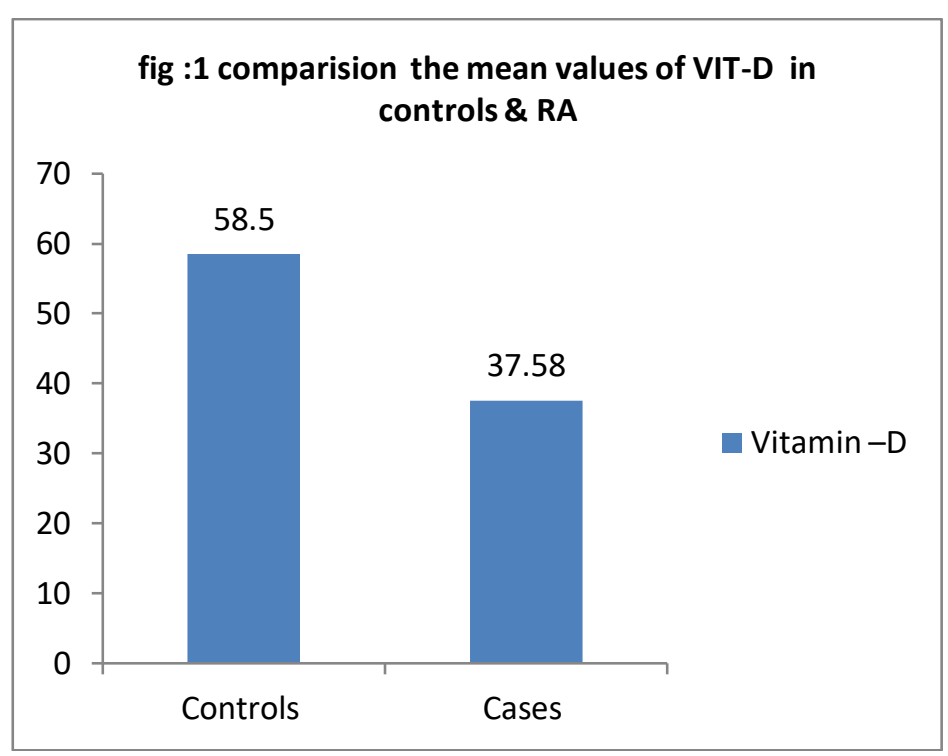

Table 2: SHOWING THE MEAN VALUES OF MDA IN CONTROLSAND RA

\begin{tabular}{|l|l|l|l|}
\hline Parameter & Controls & Cases & $\boldsymbol{p}$ value \\
\hline MDA & $3.7 \pm 2.8$ & $8.4 \pm 2.8$ & $0.001^{*}$ \\
\hline
\end{tabular}

Table 3 shows a significant $(p=0.001)$ decreased levels of vitamin $-c$ in the RA patients $(0.6 \pm 0.3 \mathrm{mg} / \mathrm{dl})$ as compared to healthy controls $(1.0 \pm 0.31 \mathrm{mg} / \mathrm{dl})$. vitamin -c levels show statistically significant decreased in cases compared to controls $(p=0.0001)$.

Table 3: SHOWING THE MEAN VALUES OF MDA IN CONTROLS AND RA

\begin{tabular}{|l|l|l|l|}
\hline Parameter & Controls & Cases & $\boldsymbol{p}$ value \\
\hline VITAMIN -C & $1.0 \pm 0.31$ & $0.6 \pm 0.3$ & $0.001^{*}$ \\
\hline
\end{tabular}




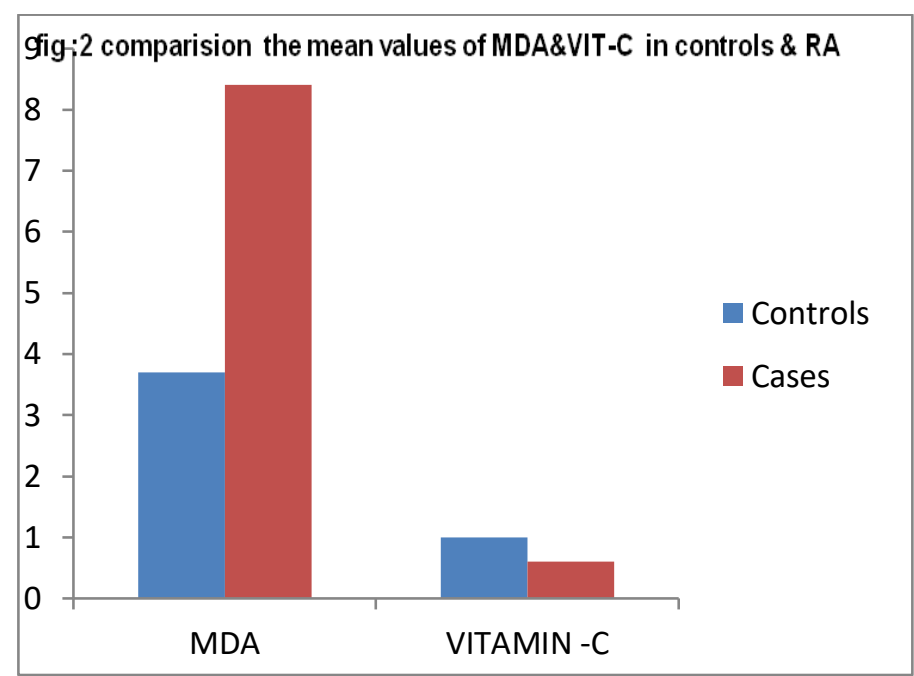

\section{Discussion}

In the present study vitamin D levels were found to be low in a group of patients with RA. Vitamin D levels have been studied in RA were found to be negatively correlated with disease activity in RA.. Vitamin D deficiency may be associated with an increased risk for the development of RA. Rossini and colleagues found an inverse association between vitamin D levels and disease activity in RA [Rossini et al. 2010]. Welsh and colleagues and Kerr and colleagues found that vitamin D deficiency is linked with disease activity in. Vitamin D is known to induce immunologic tolerance [22]. Cutolo et al. reported a significant inverse association between 25(OH)D and DAS28 in patients with active RA and Patel et al. found an inverse relationship between 25(OH)D levels and tender joint count, DAS28, and HAQ score only at disease onset, but not in patients with a disease duration longer than one to two year Thus, vitamin $\mathrm{D}$ deficiency may perturb immune tolerance and induce the development of autoimmune diseases, such as RA.[23,24] Vitamin D has immunomodulatory properties, acting on the immune system both in an endocrine and in a paracrine manner [25]. There was a negative relationship between vitamin D levels and RA disease activity in our study. It appears to regulate the immune response by a variety of mechanisms, such as decreasing antigen presentation [Bartels et al. 2010], inhibiting the proinflammatory $\mathrm{T}$ helper type 1 profile [Jirapongsananuruk et al. 2000] and inducing regulatory $\mathrm{T}$ cells [Correale et al. 2009]. 1,25(OH)2D3 suppresses proliferation and immunoglobulin production and retards differentiation of B-cell precursors into plasma cells [Chen et al. 2007]. These data support a role for vitamin $\mathrm{D}$ deficiency in the development and progression of autoimmune inflammatory conditions in general, and in particular RA

Oxidative stress being one of the important cause of various rampant diseases of modern age such as RA, cancer, osteoarthritis, osteoporosis and atherosclerosis, occurs due to the disruption of balance between body's oxidants load and antioxidants reservoir [ 26,27$]$. RA is a inflammatory autoimmune disorder .with synovial proliferation, destruction of bone and cartilage degradation. Although the etiology of RA is still not very much clear but one recent study clearly demonstrates the involvement of reactive oxygen species in the pathogenesis of the disease. Macrophages and polymorphonuclear cells present at the site of synovitis promotes the formation of reactive oxygen species and subsequent activation of inflammatory molecules which are involved in the progression of RA[28]
In our study MDA levels were found to be significantly ( $P$ $\mathrm{P}<0.001)$ elevated in the patients with RA compared to the controls. Our study supports to other studies where higher MDA levels have been reported in patients with RA[29,30,31] .In other studies Kamanli A et.al there is an elevated levels of MDA has been found in the serum, plasma and erythrocytes of RA patients [32]. Sarban S et.al there is an elevated levels of MDA has been found in the serum, plasma and erythrocytes of RA patients.[33] Hassan MQ, there is an elevated levels of MDA has been found in the serum, plasma and erythrocytes of RA patients.[34] We observed significantly low levels of antioxidants vitamin C[ $\mathrm{P}<0.001$ ]in RA patients as compared to healthy individuals. In the inflamed joint, hypoxia-reperfusion occurs which may result in increased lipolysis. During this process, some lipids may get oxidatively modified by free radicals and removed by macrophages.[35] Patients with inflammation of the synovial membrane respond relatively frequently by a reduction of indicators of antioxidants and antioxidant enzymes.[36] Our results are in agreement with other recent studies that indicate that oxidative stress generated within an inflamed joint can produce connective tissue destruction leading to joint and periarticular deformities in RA.[37-39] The level of oxidative stress is found to be much higher in patients with active disease. Further indepth knowledge about this aspect of RA.

Conclusion: our findings confirm Vitamin D deficiency in RA patients, and its association with inflammation which leads to Increased oxidative stress status, which may lead to connective tissue degradation leading to joint and periarticular deformities in rheumatoid arthritis.

Funding : This research did not receive any specific grant from any funding agency in the public, commercial or notfor-profit sector.

Declaration of interest: The authors declare there exist no conflict of interest that could be perceived as prejudicing the impartiality of the research reported.

\section{References}

1. Alamanos Y, Drosos AA: Epidemiology of adult rheumatoid arthritis. Autoimmunity Reviews 2005; (4)3: 130-136. 2. Dayer JM:

2. McInnes, I. and Schett, G. (2011) The pathogenesis of rheumatoid arthritis. N Engl J Med 365: 2205-2219.

3. Choy, E. (2012) Understanding the dynamics: pathways involved in the pathogenesis of rheumatoid arthritis. Rheumatology (Oxford) 51(Suppl. 5): v3-v11.

4. Keystone, E., Smolen, J. and van Riel, P. (2012) Developing an effective treatment algorithm for rheumatoid arthritis. Rheumatology (Oxford) 51(Suppl. 5): v48-v54.

5. Merlino, L., Curtis, J., Mikuls, T., Cerhan, J., Criswell, L. and Saag, K.; Iowa Women's Health Study (2004) Vitamin D intake is inversely associated with rheumatoid arthritis: results from the Iowa Women's Health Study. Arthritis Rheum 50: 72-77

6. Holick, M. (2011) Vitamin D: evolutionary, physiological and health perspectives. Curr Drug Targets 12: 4-18. 
7. Mason, R., Sequeira, V. and Gordon-Thomson, C. (2011) Vitamin D: the light side of sunshine. Eur J ClinNutr 65: 986-993.

8. M. Cutolo, K. Otsa, M. Uprus, S. Paolino, and B. Seriolo, "Vitamin D in rheumatoid arthritis," Autoimmunity Reviews, vol. 7, no. 1, pp. 59-64, 2007.

9. Song, G., Bae, S. and Lee, Y. (2012) Association between vitamin $\mathrm{D}$ intake and the risk of rheumatoid arthritis: a meta-analysis. ClinRheumatol 2 September [Epub ahead of print].

10. Holick MF: Vitamin D deficiency. N Engl J Med 2007, 357:266-281.

11. Holick MF: Sunlight and vitamin D for bone health and prevention of autoimmune diseases, cancers, and cardiovascular disease. Am J ClinNutr 2004, 80:1678S1688 .

12. . Kroger H, Penttila IM, Alhava EM: Low serum vitamin D metabolites in women with rheumatoid arthritis. Scand J Rheumatol 1993, 22:172-177.

13. 11. Rico H, Revilla M, Alvarez De Buergo M, Villa LF: Serum osteocalcin and calcitropic hormones in a homogeneous group of patients with rheumatoid arthritis: its implication in the osteopenia of the disease. ClinExpRheumatol 1993, 11:53-56.

14. 12. Oelzner P, Muller A, Deschner F, Huller M, Abendroth K, Hein G, Stein G: Relationship between disease activity and serum levels of vitamin D metabolites and PTH in rheumatoid arthritis. Calcif Tissue Int 1998, 62:193-198.

15. 13. Aguado $\mathrm{P}$, del Campo MT, Garces MV, Gonzalez-Casaus ML, Bernad M, Gijon-Banos J, Martín Mola E, Torrijos A, Martínez ME: Low vitamin D levels in outpatient postmenopausal women from a rheumatology clinic in Madrid, Spain: their relationship with bone mineral density. OsteoporosInt 2000, 11:739-744.

16. Solomon DH, Finkelstein JS, Shadick N, LeBoff MS, Winalski CS, Stedman M, Glass R, Brookhart MA, Weinblatt ME, Gravallese EM: The relationship between focal erosions and generalized osteoporosis in postmenopausal women with rheumatoid arthritis. Arthritis Rheum 2009, 60:16241631.

17. 15. Craig SM, Yu F, Curtis JR, Conn DL, Jonas B, Callahan LF, Smith EA, Moreland LW, Bridges SL Jr, Mikuls TR: Vitamin D status and its associations with disease activity and severity in African Americans with recent-onset rheumatoid arthritis. J Rheumatol 2010, 37:275-281.

18. Patel S, Farragher T, Berry J, Bunn D, Silman A, Symmons D: Association between serum vitamin D metabolite levels and disease activity in patients with early inflammatory polyarthritis. Arthritis Rheum 2007, 56:21432149.

19. G. S. Kerr, I. Sabahi, J. S. Richards et al., "Prevalence of vitamin D insufficiency/deficiency in rheumatoid arthritis and associations with disease severity and activity," The Journal of Rheumatology, vol. 38, no. 1, pp. 53-59, 2011.

20. M. Varenna, M. Manara, F. Cantatore et al., "Determinants and effects of vitamin D supplementation on serum 25-Hydroxyvitamin levels in patients with rheumatoid arthritis," Clinical and Experimental Rheumatology, vol. 30, no. 5, pp. 714-719, 2012.

21. Vivek Kumar1,3, Jaya Prakash2 , Varsha Gupta1* and Khan MY3. Antioxidant Enzymes in Rheumatoid Arthritis ;Kumar et al., J Arthritis 2016, 5:4.

22. Weiss, S. (2011) Bacterial components plus vitamin D: the ultimate solution to the asthma (autoimmune disease) epidemic? J Allergy ClinImmunol 127: 1128-1130.

23. Cutolo $M$, Otsa $K$, Laas $K$, Yprus $M$, Lehtme R, Secchi ME, Sulli A, Paolino S, Seriolo B: Circannual vitamin D serum levels and disease activity in rheumatoid arthritis: Northern versus Southern Europe. ClinExpRheumatol 2006, 24:702-704.

24. Patel S, Farragher T, Berry J, Bunn D, Silman A, Symmons D: Association between serum vitamin D metabolite levels and disease activity in patients with early inflammatory polyarthritis. Arthritis Rheum 2007, 56:21432149. 18. Isaia G, Giorgino R, Rini GB, Bevilacqua M, Maugeri D, Adami S: Prevalen

25. Mora, J.R., Iwata, M. and von Andrian, U.H. (2008) Vitamin effects on the immune system: vitamins A and D take centre stage. Nat Rev Immunol 8: 685-698.

26. IfigeniaKostoglou-Athanassiou,

PanagiotisAthanassiou, AikateriniLyraki, IoannisRaftakis and Christodoulos Antoniadis; Vitamin D and rheumatoid arthritis ;TherAdvEndocrinolMetab (2012) 3(6) 181-187.

27. Demirbag R, Yilmaz R, Erel O, Gultekin U, Asci D, Elbasan $\mathrm{Z}$. The relationship between potency of oxidative stress and severity of dilated cardiomyopathy. Can J Cardiol. 2005; 21:851-5. PMID: 16107908 28. Ozgocmen S, Ozyurt $\mathrm{H}$, Sogut S, Akyol O. Current concepts in the pathophysiology of fibromyalgia: the potential role of oxidative stress and nitric oxide. Rheumatol Int. 2006; 26:585-597. PMID: 16328420 29. Henrotin Y, Kurz B, Aigner T. Oxygen and reactive oxygen species in cartilage degradation: friends or foes? OsteoarthrCartil. 2005; 13:643-654. PMID: 15936958.

28. Somaiya Mateen1 *, ShaguftaMoin1 , Abdul Qayyum Khan2, Atif Zafar3, Naureen Fatima1 Increased Reactive Oxygen Species Formation and Oxidative Stress in Rheumatoid Arthritis.

29. Taysi S, Polat F, Gul M, Sari RA, Bakan E. Lipid peroxidation, some extracellular antioxidants, and antioxidant enzymes in serum of patients with rheumatoid arthritis. RheumatolInt 2002; $21: 200-4$.

30. Akyol O, Isci N, Temel I, Ozgocmen S, Uz E. The relationships between plasma and erythrocyte antioxidant enzymes and lipid peroxidation in patients with rheumatoid arthritis. Joint Bone Spine 2001; 68 : 311-7.

31. Cimen MY, Cimen OB, Kacmaz , Ozturk HS, Yorgancioglu R, Durak I. Oxidant/antioxidant status of the erythrocytes from patients with rheumatoid arthritis. ClinRheumatol 2000; $19: 275-7$.

32. Kamanli A, Naziroğlu M, Aydilek N, Hacievliyagil C. Plasma lipid peroxidation and antioxidant levels in patients with rheumatoid arthritis. Cell BiochemFunct. 2004; 22: 5357. PMID: 14695655 
33. Sarban S, Kocyigit A, Yazar M, Isikan UE. Plasma total antioxidant capacity, lipid peroxidation, and erythrocyte antioxidant enzyme activities in patients with rheumatoid arthritis and osteoarthritis. ClinBiochem. 2005; 38:981-986. PMID: 16150434

34. Hassan MQ, Hadi RA, Al-Rawi ZS, Padron VA, Stohs SJ. The glutathione defense system in the pathogenesis of rheumatoid arthritis. J ApplToxicol. 2001; 21:69-73. PMID: 11180282 .

35. 0 Kasama T, Kobayashi K, Sekine F, et al. (1988) Follow-up study of lipid peroxides, SOD and glutathione peroxidase in synovial membrane, serum and liver of young and old mice with collagen-induced arthritis. Life Sci 43, 1887-96.

36. Kucera M, Racek J, Holecek V (1996) Free 02 radicals and rheumatic disease. VnitrLek 42, 320-33.

37. Kasama T, Kobayashi K, Sekine F, et al. (1988) Follow-up study of lipid peroxides, SOD and glutathione peroxidase in synovial membrane, serum and liver of young and old mice with collagen-induced arthritis. Life Sci 43, 1887-96.

38. 38 Kaneda H (1982) A study on the lipid peroxide and its scavenging enzyme in RA. Nippon SeikeigekaGakkiZusshi 56, 387-97.

$39 . \quad 39$ Igari T, Kaneda H, Horiuchi S, Ono S (1982) A remarkable increase of SOD activity in synovial fluid from patients with RA. ClinOrthop 162, 282-7. 